
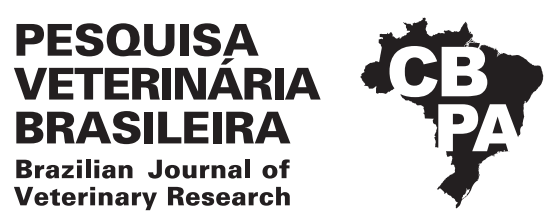

Pesq. Vet. Bras. 38(7):1344-1350, julho 2018 DOI: 10.1590/1678-5150-PVB-5282

Artigo Original

ISSN 0100-736X (Print)

ISSN 1678-5150 (Online)

\title{
Soroprevalência da infecção por Corynebacterium pseudotuberulosis em caprinos no Nordeste brasileiro utilizando técnica de imunoabsorção enzimática (ELISA-indireto) ${ }^{1}$
}

Areano M. Farias², José R.A. Alves², Francisco S.F. Alves ${ }^{3}$, Raimundo R. Pinheiro ${ }^{3}$, Patrícia Y. Faccioli-Martins ${ }^{3}$, Ana M.C. Lima ${ }^{3}$, Sérgio S. Azevedo² e Clebert J. Alves²*

\begin{abstract}
Farias A.M., Alves J.R.A., Alves F.S.F., Pinheiro R.R., Faccioli-Martins P.Y., Lima A.M.C., Azevedo S.S. \& Alves C.J. 2018. [Serological study on Corynebacterium pseudotuberculosis infection in goats in the Brazilian Northeast using enzyme-linked immunosorbent assay (ELISA-indirect)] Estudo sorológico sobre infecção por Corynebacterium pseudotuberulosis em caprinos no Nordeste brasileiro utilizando técnica de imunoabsorção enzimática (ELISA-indireto). Pesquisa Veterinária Brasileira 38(7):1344-1350. Programa de Pós-Graduação em Medicina Veterinária, Universidade Federal de Campina Grande, Av. Universitária s/n, Santa Cecília, Patos, PB 58700-970, Brasil. E-mail: clebertja@uol.com.br

Goat farming in the Northeast region of Brazil plays an important socioeconomic and strategic role. The rusticity of this activity in this region, allied with its rapid expansion in other states, has caused losses in its production chain in regional and national levels, caused by infectious diseases, especially caseous lymphadenitis (CL), a widespread goat herds disease which has been causing serious economic loss to this activity. Although CL has been detected as an endemic problem in the Brazilian Northeast, a comprehensive and more recent analysis of this prevalence in Brazilian goats is necessary. The objective of this study was to determine the frequency of anti-Corynebacterium pseudotuberculosis antibodies in five of nine states of the northeast region of Brazil. Serum samples were collected from 2571 goats from 218 farms in five states in the Northeast region of Brazil, collected between 2010 and 2012. The diagnosis of C. pseudotuberculosis infection was made using the ELISA-indirect technique. In 88.5\% (193/218) of the investigated properties, at least one goat was seropositive for C. pseudotuberculosis, suggesting that the agent is widespread in Northeast herds, with the highest prevalence found in Rio Grande do Norte (94.5\%) and the lowest one in the state of Sergipe (70.3\%). A total of $783(30.45 \%$; 95\% CI $=28.71-32.26 \%)$ seropositive goats were found, and the highest prevalence among animals was found in Piauí (41.4\%) and the lowest in the state of Sergipe (22.5\%). Out of a total of 279 breeding herds, 106 (37.99\%) were seropositive, standing out the Rio Grande do Norte, with a total of $45.30 \%$, and Piauí $46.8 \%$ of positive breeding for CL. A total of the 1420 tested matrices, 599 (42.1\%) presented positive serology for C. pseudotuberculosis. Among the States, this distribution also remained similar, standing out Rio Grande do Norte with $47.5 \%$, and Piauí with 59.5\% of positive matrices for CL. Among 872 young goats evaluated, 78 (8.9\%) were seropositive for CL, observing a statistical difference in the frequency of soropositivity obtained between adults and young adults $(\mathrm{P}<0.001)$. The necessity to diagnose the disease in goat herds in the Northeast region is reinforced for the possible implementation of disease control programs and more precise measures to manage CL along with goat farmers.
\end{abstract}

INDEX TERMS: Serology, Corynebacterium pseudotuberculosis, infection, goats, Brazil, enzyme-linked immunosorbent, ELISA-indirect, caseous lymphadenitis, bacterioses.

\footnotetext{
${ }^{1}$ Recebido em 26 de julho de 2017.

Aceito para publicação em 1 de dezembro 2017.

${ }^{2}$ Unidade Acadêmica de Medicina Veterinária (UAMV), Universidade Federal de Campina Grande (UFCG), Av. Universitária s/n, Cx. Postal 61, Santa Cecília, Patos, PB 58700-970, Brasil.*Autor para correspondência: clebertja@uol.com.br

${ }^{3}$ Departamento de Sanidade Animal, Embrapa Caprinos e Ovinos (CNPC), Sobral, CE 62010-970, Brasil.
}

RESUMO.- A caprinocultura na região Nordeste do Brasil desempenha importante função socioeconômica e estratégica. A rusticidade desta atividade nesta região, aliada a sua rápida expansão em outros estados, tem gerado perdas na sua cadeia produtiva a nível regional e nacional, causadas por doenças infecciosas, destacando-se a Linfadenite Caseosa (LC), afecção 
amplamente difundida nos rebanhos caprinos, acarretando sérios prejuízos econômicos à atividade. Embora LC tenha sido detectada como um problema endêmico no nordeste brasileiro, uma análise abrangente e mais recente desta prevalência nos rebanhos caprinos brasileiros se faz necessária. 0 objetivo desse estudo foi determinar a frequência de anticorpos anti-Corynebacterium pseudotuberculosis em cinco dos nove estados que compõem a região Nordeste do Brasil. Foram processadas amostras de soro de 2571 caprinos provenientes de 218 propriedades rurais oriundas de cinco estados da região Nordeste do Brasil, coletadas entre os anos de 2010 a 2012. 0 diagnóstico da infecção por C. pseudotuberculosis foi realizado pela técnica de ELISA-indireto. Em 88,5\% (193/218) das propriedades investigadas, pelo menos um caprino foi soropositivo para C. pseudotuberculosis, sugerindo que o agente se encontra disseminado nos rebanhos do Nordeste, com a maior prevalência encontrada no Rio Grande do Norte $(94,5 \%)$ e a menor no estado de Sergipe (70,3\%). Foram identificados 783 (30,4\%; IC 95\%=28,7-32,2\%) caprinos soropositivos, com a maior prevalência entre animais encontrada no Piauí $(41,4 \%)$ e a menor no estado de Sergipe $(22,5 \%)$. De um total de 279 reprodutores avaliados, 106 (37,9\%) resultaram soropositivos, destacando-se o Rio Grande do Norte, com 45,30\%, e Piauí com 46,8\% dos reprodutores positivos para LC. Das 1420 matrizes testadas, 599(42,1\%) apresentaram sorologia positiva para C. pseudotuberculosis. Entre os estados esta distribuição também se manteve semelhante, destacando-se o Rio Grande do Norte, com 47,5\% e Piauí com 59,5\% das matrizes positivos para LC. Entre os 872 caprinos jovens avaliados, 78 (8,9\%) foram soropositivos para LC, observando-se uma diferença estatística na frequência de sopositividade obtidas entre os adultos e os jovens $(\mathrm{P}<0,001)$. Reforça-se a necessidade do diagnóstico da enfermidade em rebanhos caprinos da região Nordeste para possível implementação de programas de controle da doença e medidas mais precisas no manejo da LC junto aos criadores de caprinos.

TERMOS DE INDEXAÇÃO: Sorologia, infecção, Corynebacterium pseudotuberulosis, caprinos, Nordeste Brasileiro, imunoabsorção enzimática, ELISA-indireto, linfadenite caseosa, bacterioses.

\section{INTRODUÇÃo}

A caprinocultura é uma das práticas pecuárias mais antigas do Brasil, cuja origem remonta aos tempos da ocupação portuguesa. Está distribuída nas cinco grandes regiões do país, predominando no Nordeste, que conta com efetivo de mais de nove milhões de caprinos, 92,6\% do efetivo nacional. Destaca-se atualmente como atividade econômica de importância estratégica nesta região, sendo direcionada para a produção de couro, carne, leite e seus derivados (IBGE 2015, SEBRAE 2009).

A cadeia produtiva da pecuária caprina envolve mais de um milhão de estabelecimentos rurais no Nordeste brasileiro, possuindo importante função socioeconômica, seja diretamente para alimentação das famílias ou na geração de renda (Moreira \& Guimarães Filho 2011, SEBRAE 2009, Teixeira 2009). Entretanto, a rusticidade da caprinocultura nordestina, aliada à sua rápida expansão na última década, tem gerado déficits sanitários na cadeia produtiva nacional (Alencar et al. 2010, Guimarães et al. 2011, Seyffert et al.
2010), provocados por doenças infecciosas, com perdas pelas altas taxas de morbidade e mortalidade (Medeiros et al. 2005, Pinheiro et al. 2000). Dentre as doenças infecciosas de impacto econômico para a caprinocultura, destaca-se a linfadenite caseosa (LC) (Seyffert et al. 2010).

A LC é causada por Corynebacterium pseudotuberculosis, e se caracteriza pela formação de abscessos nos linfonodos superficiais e viscerais nos pequenos ruminantes (Faccioli-Martins et al. 2014). É uma doença crônica, subclínica e cosmopolita, afetando principalmente caprinos, ovinos e ocasionalmente bovinos, equinos e mais raramente, o ser humano (Baird \& Fontaine 2007, Fontaine \& Baird 2008). Os prejuízos desta doença relacionam-se à sua alta incidência e morbidade nos animais acometidos, comprometimento das funções orgânicas: baixo de ganho de peso, problemas na produção de leite caprino, depreciação da pele, custos com tratamento, depreciação/condenação de carcaças e a morte dos animais acometidos (Brown et al. 1987, Paton et al. 1994). No Brasil, estima-se que a maioria dos rebanhos caprinos e ovinos estejam afetados (Souza et al. 2011), e alguns estados já apresentaram prevalência superior a 50\% (Magalhães 1985, Guimarães et al. 2011).

O isolamento e a identificação de C. pseudotuberculosis são considerados padrão ouro no diagnóstico da LC. Contudo, esta técnica se mostra pouco prática e demorada, o que motiva a necessidade da procura por métodos alternativos que possam agilizar o resultado e que contribua para o controle da doença; desta forma, a técnica de ELISA (Enzyme-Linked Immunosorbent Assay) para C. pseudotuberculosis, por apresentar sensibilidade e especificidade adequadas, pode ser uma ferramenta diagnóstica com maior utilidade no controle da LC em rebanhos comerciais e com aplicação de escolha em programas sanitários (Faccioli-Martins et al. 2014).

Levantamentos sorológicos têm sido realizados em alguns estados brasileiros, apesar de poucos trabalhos com a técnica de ELISA-indireto, estes evidenciaram elevada frequência de LC nos rebanhos. No Ceará, Carmo et al. (2010) observaram frequência de $26,2 \%$ em caprinos e $84,5 \%$ das propriedades positivas para LC; no Distrito Federal, Carmo et al. (2012) obtiveram prevalência de $44 \%$ em ovinos, com $50 \%$ das propriedades positivas. Seyffert et al. (2010) e Guimarães et al. (2009), no estado de Minas Gerais, observaram soroprevalências de $78,9 \%$ em caprinos e 75,8\% em ovinos, com 98\% e 95,9\% dos rebanhos apresentando pelo menos um animal soropositivo para LC, respectivamente.

A importância da LC no Brasil pode ser estimada pelo aumento da participação dos pequenos ruminantes na pecuária nacional e sua relação com o impacto econômico desta doença (Guimarães et al. 2009, Seyffert et al. 2010, Carmo et al. 2012, Faccioli-Martins et al. 2014). Embora a LC tenha sido detectada como problema endêmico na mais importante área de produção de caprinos do país, o Nordeste brasileiro (Brown et al. 1987), uma análise abrangente e mais recente desta prevalência nos rebanhos caprinos brasileiros se faz necessária. 0 aumento da participação da caprinocultura em alguns estados e a pouca importância da LC dada por autoridades e proprietários, torna esta situação preocupante. Poucos estudos sorológicos têm sido realizados no Brasil com relação às doenças que afetam os pequenos ruminantes, provavelmente devido a dificuldades na obtenção de insumos e infraestrutura necessária para realização das técnicas. Diante desta situação, há necessidade de se determinar 
indicadores epidemiológicos da LC nos rebanhos caprinos da região Nordeste. Dessa forma, o objetivo desse estudo foi determinar a prevalência de caprinos soropositivos para LC de cinco estados da região Nordeste do Brasil.

\section{MATERIAL E MÉTODOS}

A região Nordeste do Brasil abrange uma área de mais de 1,5 milhões de km² (18\% do território brasileiro), situada abaixo da linha do equador, com predomínio de clima semiárido e bioma típico de Caatinga. Divide-se em quatro sub-regiões (Zona da Mata, Agreste, Sertão e Meio-Norte), composta por nove estados da Federação (Bahia, Ceará, Pernambuco, Paraíba, Rio Grande do Norte, Piauí, Maranhão, Alagoas e Sergipe) (ASA Brasil 2013).

Foram utilizados caprinos adultos e jovens, de ambos os sexos, provenientes de propriedades rurais oriundas de microrregiões com densidade populacional significativa de rebanhos caprinos, nos cinco estados do Nordeste: Paraíba, Rio Grande do Norte, Ceará, do Piauí e Sergipe. A adesão dos proprietários foi voluntária. A inclusão das propriedades foi por amostragem não probabilística, através de sorteio aleatório de propriedades elencadas previamente, através de listas cedidas por associações de criadores, agências de defesa estadual, secretaria de agricultura e SEBRAE. 0 número mínimo de propriedades a serem visitadas foi calculado com o uso da fórmula para amostras simples aleatórias (Thrusfield 2007), levando-se em consideração os seguintes parâmetros: prevalência de propriedades com animais soropositivos de 98\% (Seyffert et al. 2010), erro amostral de $5 \%$ e nível de confiança de $95 \%$. Por esses parâmetros seria necessário n amostral de 30 propriedades por estado, no entanto, a amostragem final constou de 62 propriedades na Paraíba, 55 no Rio Grande do Norte, 40 no Ceará, 34 no Piauí e 27 propriedades, devido a perdas por questões operacionais, no estado de Sergipe. A amostragem foi estratificada segundo a composição aproximada dos rebanhos, definida como: $60 \%$ de matrizes, $35 \%$ de jovens (seis a doze meses) e todos os reprodutores adultos. Em cada propriedade foi coletado material de quinze caprinos, ou então de todos os animais existentes na propriedade caso esse número fosse inferior ou igual a 15.

Foram colhidas amostras de sangue de 2.571 caprinos provenientes de 218 propriedades rurais de 50 municípios dos cinco estados (Fig.1). As amostras foram coletadas entre nos anos de 2010 a 2012, entre os meses de Maio a Julho. Após a contenção do animal e assepsia local com solução de álcool iodado, as amostras de sangue foram coletas por punção de veia jugular, utilizando agulhas descartáveis,

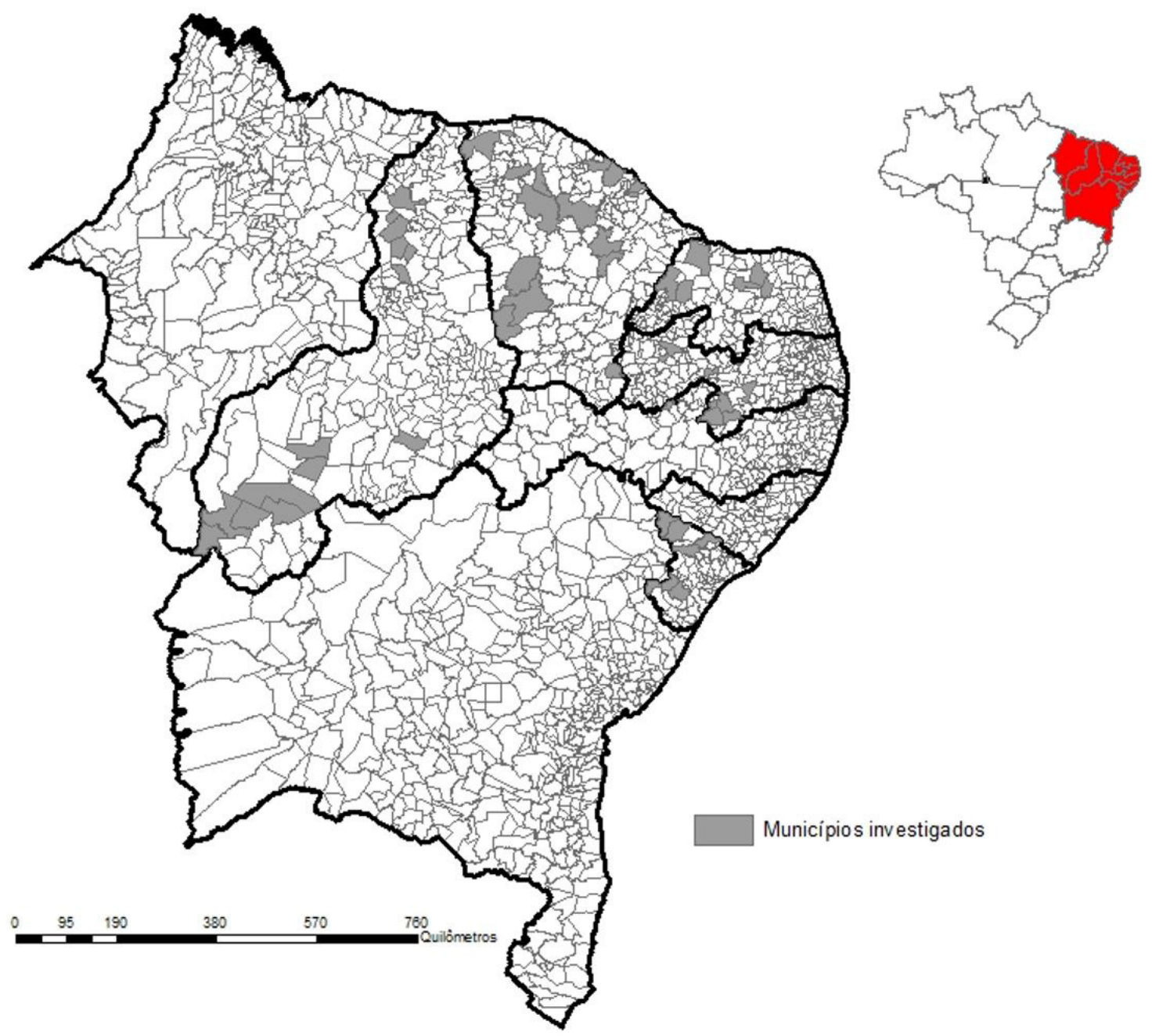

Fig.1. Distribuição geográfica dos municípios investigados nos cinco estados do Nordeste do Brasil (Paraíba, Rio Grande do Norte, Ceará, Piauí, Sergipe). 
estéreis, uma para cada animal em tubos a vácuo. Após a realização das coletas, as amostras de sangue foram encaminhadas para o Laboratório de Bacteriologia da Embrapa Caprinos e Ovinos/CNPC, Sobral/CE. Os tubos com as amostras de sangue foram mantidos à temperatura ambiente até a completa retração do coágulo com posterior centrifugação. Em seguida, as amostras foram separadas, colocadas em microtubos e previamente identificadas e mantidas a $-20^{\circ} \mathrm{C}$ para serem posteriormente utilizadas nos testes sorológicos.

Para a realização dos testes de ELISA-indireto, utilizou-se a metodologia descrita por Carminati (2005), com modificações desenvolvidas pela Empresa Brasileira de Pesquisa Agropecuária (Embrapa Caprinos e Ovinos/CNPC, Sobral/CE). O antígeno foi produzido a partir de cultura de $C$. pseudotuberculosis da cepa ovina 02/ 2014 (BRM 029971) de 72 horas em caldo BHI (Brain Heart Infusion Broth - Acumedia $\left.{ }^{\circledR}\right)$ adicionado de 0,1\% de Tween 80 confeccionado conforme Paule et al. (2004). Esse teste apresentou sensibilidade de 93,5\% e especificidade de 99,0\%.

Cada microplaca de poliestireno de fundo chato (F96 Maxisorp ${ }^{\circledR}$ - Nunc/M9410-1CS) com 96 poços foi sensibilizada com antígeno de C. pseudotuberculosis, diluído em tampão carbonato/bicarbonato $0,05 \mathrm{M} \mathrm{pH} 9,6$, incubada a $4^{\circ} \mathrm{C}$ overnight. Após duas lavagens, com solução de lavagem ( $\mathrm{NaCl}$, Tween 20 - Sigma-Aldrich $\left.{ }^{\circledR} / \mathrm{S} 9625 ; \mathrm{P} 1379\right)$, a microplaca foi bloqueada com solução de bloqueio (caseína 2\%) (Caseína - Sigma-Life Science ${ }^{\circledR} / 5890$ ), a seguir incubada a $37^{\circ} \mathrm{C}$ por 45 minutos. Os soros teste foram previamente diluídos em PBSCaseína na proporção de 1:100, em seguida adicionados à microplaca com posterior incubação a $37^{\circ} \mathrm{C}$ por 30 minutos. Após sequência de cinco lavagens com solução de lavagem, adicionou-se imunoglobulina de coelho anti-imunoglobulina de caprino, conjugada à peroxidase (Anti-Goat IgG (Whole molecule) - Sigma-Life Science ${ }^{\circledR} /$ A5420-1ML), diluída em PBS-Caseína, com posterior incubação à $37^{\circ} \mathrm{C}$ por 30 minutos. Em seguida foi realizada sequência de cinco lavagens em solução de lavagem e incubação com solução reveladora (Tetramethylbenzidine-Sigma-LifeScience ${ }^{\circledR} / \mathrm{P9029}$ ),por15minutosàtemperatura ambiente e ao abrigo da luz. A reação foi interrompida acrescentando-se $\mathrm{H}_{2} \mathrm{SO}_{4}$ (Êxodo Cientifico ${ }^{\circledR} /$ AS09591RA) 1:20, e a placa levada imediatamente ao leitor de ELISA (Thermo Eléctron oy - Modelo Multiscan FC N/S 357-906416) usando-se filtro de 490 $\mathrm{nm}$.

Para a comparação das frequências de soropositividade entre as categorias de animais (reprodutores, matrizes e jovens) por estado, foi utilizado o teste de qui-quadrado particionado com nível de significância de $5 \%$. As análises foram efetuadas com o programa BioEstat 5.03 (Ayres et al. 2007).
O projeto foi protocolado no Comitê de Ética em Pesquisa (CEP) do Centro de Saúde e Tecnologia Rural (CSTR/UFCG) sob o número $125 / 2016$.

\section{RESULTADOS}

Dos 2571 caprinos avaliados, 783 (30,4\%; IC 95\%=28,7-32,2\%) foram soropositivos, sendo a menor prevalência de animais observada em Sergipe (22,5\%) e a maior no Piauí $(41,4 \%)$. De um total de 279 reprodutores avaliados, $106(37,9 \%)$ resultaram soropositivos, destacando-se o Rio Grade do Norte com (45,3\%) e o Piauí com (46,8\%). Das 1420 matrizes testadas, 599 (42,1\%) foram soropositivas, também com destaque para os estados de Rio Grade do Norte (47,5\%) e Piauí (59,5\%). Entre os 872 caprinos jovens avaliados, 78 (8,9\%) foram soropositivos, com a menor prevalência de animais no Ceará (7,09\%) e a maior na Paraíba (11,10\%) (Quadro 1). Em todos os estados, não foi observada diferença estatística nas frequências de soropositividade para reprodutores e matrizes, no entanto, as frequências para jovens foram diferentes daquelas obtidas para reprodutores e matrizes $(\mathrm{P}<0,001)$.

De acordo com os dados obtidos no presente trabalho, $88,5 \%(193 / 218)$ das propriedades investigadas apresentaram pelo menos um caprino soropositivo para Corynebacterium pseudotuberculosis. As prevalências por estado estão apresentadas no Quadro 2, e variaram de 70,3\% em Sergipe à 94,5\% no Rio Grande do Norte.

\section{DISCUSSÃO}

A elevada frequência observada nas propriedades estudadas $(88,5 \%)$ demonstra que a LC se encontra difundida no Nordeste brasileiro. Apesar de este trabalho parecer ser o primeiro a realizar uma abordagem regional em relação à linfadenite caseosa (LC) no Brasil, esta prevalência chama atenção por evidenciar cinco dos nove estados do Nordeste com uma prevalência tão elevada entre as propriedades. Estes valores aproximam-se dos observados por Carmo (2010) e Seyffert et al. (2010), que em levantamento sorológico pela técnica de ELISA-indireto para LC, encontraram prevalências de propriedades de 82,6\% e 98\% nos estados de Ceará e Minas Gerais, respectivamente, apontando desinformação e dificuldade na detecção da LC como principais motivos para a elevada prevalência nestes estados. A identificação de animais suspeitos de LC se dá usualmente pela observação dos

Quadro 1. Prevalência de caprinos testados para Corynebacterium pseudotuberculosis quanto à categoria, criados nas unidades caprinoculturas dos estados PB, RN, CE, PI e SE, entre 2010 e 2012

\begin{tabular}{|c|c|c|c|c|c|c|c|c|c|c|c|c|}
\hline \multirow[b]{2}{*}{ Estados } & \multicolumn{3}{|c|}{ Reprodutores } & \multicolumn{3}{|c|}{ Matrizes } & \multicolumn{3}{|c|}{ Jovens } & \multicolumn{3}{|c|}{ Total } \\
\hline & № total & $\begin{array}{c}\text { Positivos } \\
(\%)\end{array}$ & IC (\%) & № total & $\begin{array}{c}\text { Positivos } \\
(\%)\end{array}$ & IC (\%) & № total & $\begin{array}{c}\text { Positivos } \\
(\%)\end{array}$ & IC (\%) & № total & $\begin{array}{c}\text { Positivos } \\
(\%)\end{array}$ & IC (\%) \\
\hline Paraíba & 63 & $19(30,20)$ & $20,2-42,3$ & 451 & $172(38,10)$ & $33,7-42,6$ & 227 & $25(11,10)$ & $7,5-16,0$ & 741 & $216(29,0)$ & $26,0-32,5$ \\
\hline Ceará & 44 & $10(22,70)$ & $14,2-40,2$ & 275 & $93(33,80)$ & $28,4-39,6$ & 141 & $10(7,09)$ & $4,0-12,5$ & 460 & $113(24,0)$ & $21,0-29,0$ \\
\hline Piauí & 64 & $30(46,8)$ & $35,2-58,9$ & 205 & $122(59,5)$ & $53,0-66,0$ & 127 & $12(9,44)$ & $5,5-16,0$ & 396 & $164(41,4)$ & $37,0-46,3$ \\
\hline Total & 279 & $106(37,99)$ & $32,5-43,8$ & 1420 & $599(42,18)$ & $40,0-45,0$ & 872 & $78(8,9)$ & $7,2-11,0$ & 2571 & $783(30,5)$ & $29,0-32,2$ \\
\hline
\end{tabular}

$\overline{\mathrm{VPP}}=0,91, \mathrm{VPN}=0,96$. 
Quadro 2. Prevalência de propriedades de caprinos testados para Corynebacterium pseudotuberculosis dos estados PB, RN, CE, PI e SE, entre 2010 e 2012

\begin{tabular}{cccc}
\hline Estados & № total & Positivas (\%) & IC (\%) \\
\hline Paraíba & 62 & $58(93,5)$ & $84,5-97,4$ \\
Rio Grande do Norte & 55 & $52(94,5)$ & $85,1-98,1$ \\
Ceará & 40 & $32(80,0)$ & $65,2-89,5$ \\
Piauí & 34 & $32(94,1)$ & $80,9-89,3$ \\
Sergipe & 27 & $19(70,3)$ & $51,5-84,15$ \\
Total & 218 & $193(88,5)$ & $83,6-92,11$
\end{tabular}

$\overline{\mathrm{VPP}}=0,91, \mathrm{VPN}=0,96$.

linfonodos superficiais hipertrofiados (Alves et al. 2007), este método exige dos manejadores experiência e conhecimento técnico adequados, na avaliação das lesões sugestivas de LC nos animais, condição nem sempre executada de forma satisfatória nos rebanhos caprinos. Constata-se ainda, que na avaliação dos linfonodos hipertrofiados, nos animais acometidos, não é possível diferenciar as lesões características de Corynebacterium pseudotuberculosis dos abscessos provocados por patógenos oportunistas, a exemplo do Arcanobacterium pyogenes e da Pasteurella multocida (Nassar 2009). Apesar de ser um método simples, a palpação não é capaz de identificar os portadores assintomáticos da LC, permitindo a introdução destes animais nos rebanhos. Dessa forma, a aquisição dos animais portadores de $C$. pseudotuberculosis facilita a transmissão de LC entre os rebanhos.

Na última década, com o aumento de demanda do mercado consumidor, alguns estados têm financiado produtores e a indústria, como é o caso observado nos estados avaliados no presente trabalho, a exemplo do projeto "Leite da Paraíba" (Bandeira et al. 2007) e o "Programa do Leite" no Rio Grande do Norte (Silva 2014), que estimulam a compra da produção de leite caprino pelos governos estaduais. De modo geral a LC tem sido evidenciada sempre nas áreas do Brasil em que a atividade da pecuária de pequenos ruminantes demonstra uma importância econômica relevante, muitas vezes com o fomento de incentivos de mercado e das indústrias. Devido a rápida expansão destes setores, as situações sanitárias e conhecimentos técnicos são muitas vezes negligenciadas pelos proprietários e autoridades dentro das cadeias produtivas (Guimarães et al. 2009, Guilherme 2015), muitas vezes devido a ausência de legislação especifica para os rebanhos de pequenos ruminantes.

As menores prevalências de propriedades (70,3\%) e de animais $(22,5 \%)$ foram encontradas no estado de Sergipe. Chama a atenção deste estado a sua condição de "Zona Livre de Febre Aftosa com Vacinação", desde 2011, que diferia dos demais estados do estudo, os quais eram zonas de "BR 3 - Risco Médio" na época das coletas, em 2012. Para a um estado possuir as condição de "Zona Livre de Febre Aftosa com Vacinação" são exigidos uma melhor organização dos serviços de controle e fiscalização sanitários, dentre outros, como rigores de trânsito de susceptíveis e orientação sanitária dentro das áreas reconhecidas, contidos na Instrução Normativa no44 de 2 de outubro de 2007 (Brasil 2010), apesar de não relacionados especificamente à LC influenciaram na sua prevalência, observando-se que estas medidas também afetam a prevalência de outras infecções nos rebanhos presentes nestas zonas livres dos rigores de fiscalização em Sergipe, a prevalência de propriedades positivas neste estado ainda é elevada, sugerindo dificuldade na detecção da LC nos animais sem sintomas evidentes, necessitando de uma abordagem específica na distinção destes animais dentro dos rebanhos, bem como a criação de novas abordagens no manejo da LC.

A prevalência de LC entre reprodutores e matrizes se deu de forma semelhante entre os estados, não se observando diferenças estatísticas nas frequências de soropositividade destas categorias. Estes resultados corroboram com aqueles resultados obtidos por Seyffert et al. (2010) e Guimarães et al. (2009), que pela técnica de ELISA-indireto, também não obtiveram diferenças estatísticas relevantes entre machos e fêmeas, ressaltando maior importância ao aumento da prevalência de LC em relação aos animais mais velhos, tanto em ovinos, quanto em caprinos. A maior prevalência observada entre as matrizes no presente trabalho pode ser explicada pelo maior tempo de permanência das fêmeas nas propriedades, uma vez que a maioria das propriedades pesquisadas consistia de criações voltadas para a produção de leite. Onde o maior tempo de permanência e contato com as fêmeas positivas dentro das propriedades pode contribuir para a manutenção da doença, entre elas e o risco de disseminação no rebanho, especialmente os animais jovens.

A frequência de animais jovens positivos para LC foi baixa nesta pesquisa $(8,94 \%)$, muito inferior as prevalências observadas nos adultos, com um valor de $\mathrm{P}<0,001$. Esse fato pode ser atribuído à idade dos animais jovens (de seis a doze meses) em relação à exposição ao agente e o tempo de incubação de C. pseudotuberculosis.. Do período de incubação a aparição de abscessos podem transcorrer de 25 a 147 dias (Nassar 2009), em que outros fatores podem influenciar no tempo de resposta à infecção por C. pseudotuberculosis (Ribeiro 2009), fazendo com que esta enfermidade seja comumente observada nos animais acima de 1 ano. Apesar da baixa soroprevalência encontrada, os caprinos jovens estão expostos ao risco de infecção pela possibilidade de contato com suas mães positivas e animais mais velhos.

O diagnóstico da infecção por C. pseudotuberculosis pode ser realizado por meio do cultivo e identificação morfológica e bioquímica da bactéria, isolada a partir do material caseoso de abcessos dos animais suspeitos de LC, o teste padrão-ouro (Ribeiro 2009, Motta et al. 2010). Contudo, a pouca praticidade desta técnica é considerada um fator limitante na sua aplicabilidade em grandes contingentes de animais, por requerer maior perícia e tempo do executor, quando comparado às técnicas sorológicas. Dentre as técnicas sorológicas, o teste ELISA (Enzyme-Linked Immunosorbent Assay) tem demonstrado maior dinamismo e rapidez de 
execução, alternativo ao teste padrão-ouro preconizado para LC. Mesmo possuindo especificidade menor em comparação ao cultivo e identificação de C. pseudotuberculosis (Ribeiro 2009), as melhorias alcançadas nos últimos anos, com segurança de seu emprego e a facilidade de execução, tornaram o ELISA uma boa opção no diagnóstico da LC (Dercksen et al. 2000, Oreiby 2015). A principal dinâmica desse teste consiste na habilidade em detectar os animais assintomáticos (Faccioli-Martins et al. 2014), o principal fator crítico na disseminação de C. pseudotuberculosis em rebanhos de pequenos ruminantes. Desse modo, o emprego da técnica de ELISA na detecção de LC nos rebanhos favorece a realização de provas mais efetivas na implementação de programas de controle da doença no Brasil e para os rebanhos em nível comercial.

Padronizações do teste ELISA, para diagnóstico da LC na espécie caprina, foram realizados em vários países, como na Holanda (Dercksen et al. 2000), Alemanha (Kaba et al. 2001, Sting et al. 2012) e Canadá (Menzies et al. 2004), demonstrando variações de sensibilidade entre $81 \%$ e $97 \%$ e especificidade entre $96 \%$ e $99 \%$, essa variação na sensibilidade e especificidade dos testes se devem as diferentes padronizações e antígenos utilizados nestes estudos. No Brasil, a padronização de um teste de ELISA-indireto para LC foi proposta por Carminati (2005), utilizando antígenos obtidos de sobrenadante de cultura de C. pseudotuberculosis, comparando-o ao teste padrão-ouro e PCR, obtiveram uma sensibilidade de $93,5 \%$ e especificidade de $100 \%$. Apesar de estas pesquisas demonstrarem a possibilidade do uso de uma técnica alternativa, mais precisa e efetiva na identificação dos portadores de C. pseudotuberculosis, ainda é pequeno o número de trabalhos avaliando a situação atual da LC nos rebanhos caprinos no Brasil. Segundo Faccioli-Martins et al. (2014), esse pouco número de levantamentos sorológicos para LC, se deve a pouca quantidade de laboratórios que trabalham com diagnóstico sorológico da LC, a limitações na disponibilidade dos antígenos em alguns centros de pesquisa e ao progresso relativamente recente na padronização do ELISA-indireto. Apesar disso, muito tem sido feito para tornar esta técnica cada vez mais acessível e segura no Brasil.

A identificação dos animais infectados e sua eliminação do rebanho são os métodos mais efetivos no controle da LC. Apesar disso, o manejo usual dos pequenos ruminantes ainda se baseia na identificação dos animais suspeitos através do diagnóstico clínico, o que limita bastante seu controle na impossibilidade da detecção dos animais subclínicos (Alves et al. 2007). Segundo Campbell et al. (1982) e 0’Reilly et al. (2008), após a infecção inicial, o rebanho afetado pela LC passa a apresentar uma alta incidência de abcessos superficiais, aumentando a frequência da forma subclínica (crônica) nos anos seguintes, com o início da fase endêmica e a maior frequência de abcessos internos no rebanho. Estas condições evidenciam que a frequência de casos de LC dentro de um rebanho pode ser subestimada pela dificuldade de identificação dos animais subclínicos. Limitações técnicas inerentes a caprinocultura também pode estar interferindo diretamente nesse manejo, prejudicando o controle da LC dentro dos rebanhos. Isso demonstra a necessidade de estudos sorológicos mais abrangentes, para o estabelecimento de medidas de controle mais precisas e melhorias na abordagem da LC dentro dos rebanhos caprinos do Nordeste do Brasil.

\section{CONCLUSÕES}

A infecção por Corynebacterium pseudotuberculosis, determinada por sorologia, encontra-se amplamente disseminada nos caprinos dos estados do Nordeste do Brasil.

Os resultados revelaram ser o ELISA-indireto um teste rápido e de fácil execução, importante na detecção dos animais assintomáticos e uma técnica promissora para o monitoramento dos rebanhos caprinos na região.

Chama-se a atenção para a necessidade de estabelecimento de medidas de controle mais precisas, como o emprego do teste de ELISA-indireto para linfadenite caseosa (LC) na rotina das propriedades, no manejo dos animais assintomáticos dos rebanhos, como também melhorias na abordagem da LC junto aos criadores de caprinos, com a capacitação adequada em relação ao manejo sanitário e os riscos desta doença.

Agradecimentos.- À Coordenação de Aperfeiçoamento de Pessoal de Nível Superior (CAPES), pela concessão da bolsa de Pós-Graduação. Ao grupo de pesquisa de Sanidade Animal da Embrapa Caprinos e Ovinos/CNPC, Sobral/ CE, pela oportunidade e cooperação. Ao CNPQ/MAPA através do Edital $64 / 2008$ pelo suporte financeiro da pesquisa

\section{REFERÊNCIAS}

Alencar S.P., Mota R.A., Coelho M.C.O.C., Nascimento S.A., Abreu S.R.O. \& Castro R.S. 2010. Perfil sanitário dos rebanhos caprinos e ovinos no sertão de Pernambuco. Ciênc. Anim. Bras. 11(1):131-140. <http://dx.doi. org/10.5216/cab.v11i1.4051>

Alves F.S.F., Santiago L.B. \& Pinheiro R.R. 2007. Linfadenite caseosa: o estado da arte. Documentos 74, Embrapa Caprinos, Sobral. 57p.

ASA Brasil 2013. Articulação Semiárido Brasileiro: caracterização do semiárido brasileiro. Disponível em <http://www.asabrasil.org.br/portal/Default. asp> Acesso em 10 out. 2016.

Ayres M., Ayres Junior M., Ayres D.M. \& Santos A.A.S. 2007. BioEstat: aplicações estatísticas nas áreas das ciências bio-médicas. 5a ed. Ong Mamiraua Belém. 364p.

Baird G.J. \& Fontaine M.C. 2007. Corynebacterium pseudotuberculosis and its role in ovine caseous lymphadenitis. J. Comp. Pathol. 137(4):179-210. <http://dx.doi.org/10.1016/j.jcpa.2007.07.002> <PMid:17826790>

Bandeira D.A., Castro R.S., Azevedo E.O., Melo L.S.S. \& Melo C.B. 2007 Característica de produção da caprinocultura leiteira na região do cariri na Paraíba. Ciênc. Vet. Tróp. 10(1):29-35.

Brasil 2010. Ministério da Agricultura, Pecuária e Abastecimento. Programa de Erradicação da Febre Aftosa, PNEFA Disponível em <http://www. agricultura.gov.br/febreaftosa> Acesso em 7 dez. 2016.

Brown C.C., Olander H.J. \& Alves S.F. 1987. Synergistic hemolysis-inhibition titers associated with caseous lymphadenitis in a slaughterhouse survey of goats and sheep in Northeastern Brazil. Can. J. Vet. Res. 47(7):14611463. <PMid:3567751>

Campbell S.G., Ashfaq M.K. \& Tashjian J.J. 1982. Caseous lymphadenitis in goats in the USA. Proc. 3rd International Conference on Goat production and Disease, Tucson, Arizona, p.449-454.

Carminati R. 2005. Estudo da sensibilidade e especificidade de quatro testes Elisa e utilização da técnica de Pcr para o diagnóstico de linfadenite caseosa em caprinos. Dissertação de Mestrado. Disponível em <https://repositorio. ufba.br/ri/bitstream/ri/20124/1/Disserta\%C3\%A7\%C3\%A3o_ICS_\%20 \%20Renato\%20Carminati.pdf> Acesso em 21 mai. 2018.

Carmo F.B. 2010. Perfil soroepidemiológico da linfadenite caseosa em caprinos no Ceará, Brasil. Dissertação de Mestrado. Disponível em: <http://www. bibliotecadigital.ufmg.br/dspace/handle/1843/SMOC-9HHJTP> Acesso em 18 dez. 2016. 
Carmo F.B., Guimarães A.S., Pauletti R.B., Lage A.P., Gonçalves V.S.P., Meyer R., Portela R.W.D., Miyoshi A., Azevedo V., Gouveia A.M.G. \& Heinemann M.B. 2012. Prevalência de anticorpos contra a linfadenite caseosa em criações comerciais de ovinos no Distrito Federal, Brasil. Arqs Inst. Biológico, São Paulo, 79(2):293-298.

Dercksen D.P., Brinkhof J.M.A., Dekker-Nooren T., Maanen K.V., Bode C.F., Baird G. \& Kamp E.M. 2000. A comparison of four serological tests for the diagnosis of caseous lymphadenitis in sheep and goats. Vet. Microbiol. 75(2):167-175. <http://dx.doi.org/10.1016/S0378-1135(00)00217-0> <PMid:10889407>

Faccioli-Martins P.Y., Alves F.S.F. \& Pinheiro R.R. 2014. Linfadenite caseosa: perspectivas no diagnóstico, tratamento e controle. Documentos 113 Embrapa Caprinos e Ovinos, Sobral, 71p. Disponível em <http://www. cnpc.embrapa.br/publicacoes/> Acesso em 14 set. 2016.

Fontaine M.C.A. \& Baird G.J. 2008. Caseous lymphadenitis. Small Ruminant Res. 76(1-2):42-48. <http://dx.doi.org/10.1016/j.smallrumres.2007.12.025>

Guilherme R.F. 2015. Caracterização epidemiológica dos lentivírus de pequenos ruminantes na região do semiárido paraibano, Brasil. Tese de Doutorado, Universidade Federal de Campina Grande. Disponível em <http://www.cstr ufcg.edu.br/ppgmv/dissertacoes/teses/tese_2015/6_ricardo_guilherme. pdf> Acesso em 18 dez. 2016

Guimarães A.S., Carmo F.B., Pauletti R.B., Seyffert N., Ribeiro D., Lage A.P., Heinemann M.B., Miyoshi A., Azevedo V. \& Gouveia A.M.G. 2011. Caseous lymphadenitis: epidemiology, diagnosis, and control. IIOAB J. 2(2):33-43.

Guimarães A.S., Seyffert N., Bastos B.L., Portela R.W.D., Meyer R., Carmo F.B., Cruz J.C.M., Mcculloch J.A., Lage A.P., Heinemann M.B., Miyoshi A., Azevedo V. \& Gouveia A.M.G. 2009. Caseous lymphadenitis in sheep flocks of the state of Minas Gerais, Brazil: Prevalence and management surveys. Small Ruminant Res. 87(1/3):86-91. <http://dx.doi.org/10.1016/j. smallrumres.2009.09.027>

IBGE 2015. Pesquisa Pecuária Municipal. Instituto Brasileiro de Geografia e Estatística. Disponível em <http://www.ibge.gov.br/home/estatistica/ economia/ppm/2015/default.shtm> Acesso em 9 nov. 2016

Kaba J., Kutschke L. \& Gerlach G.F. 2001. Development of an ELISA for the diagnosis of Corynebacterium pseudotuberculosis infections in goats. Vet. Microbiol. 78(2):155-163. <http://dx.doi.org/10.1016/S03781135(00)00284-4><PMid:11163705>

Magalhães H.H. 1985. Diagnóstico de situação da caprinocultura em algumas microrregiões dos estados de Minas Gerais e Rio de Janeiro. Revta Cabra e Bodes (1):5-7.

Medeiros J.M., Tabosa I.M., Simões S.V.D., Nóbrega Júnior J.E., Vasconcelos J.S. \& Riet-Correa F. 2005. Mortalidade perinatal em caprinos no Semiárido da Paraíba. Pesq. Vet. Bras. 25(4):201-206. <http://dx.doi.org/10.1590/ S0100-736X2005000400002>

Menzies P.I., Hwang Y.-T. \& Prescott J.F. 2004. Comparison of an interferoninterferon- $\gamma$ to a phospholipase D enzyme-linked immunosorbent assay for diagnosis of Corynebacterium pseudotuberculosis infection in experimentally infected goats. Vet. Microbiol. 100(1/2):129-137. <http:// dx.doi.org/10.1016/j.vetmic.2004.01.012> <PMid:15135521>

Moreira J.N. \& Guimarães Filho C. 2011. Sistemas tradicionais para a produção de caprinos e ovinos, p.49-68. In: Voltolini T.V. (Ed.), Produção de Caprinos e Ovinos no Semiárido. Embrapa Semiárido, Petrolina.

Motta R.G., Cremasco A.C.M. \& Ribeiro M.G. 2010. Infecções por Corynebacterium pseudotuberculosis em animais de produção. Vet. Zootec. 17(2):200-213.
Nassar A.F.C. 2009. Linfadenite Caseosa ou "mal do Caroço". Instituto Biológico, São Paulo. Disponível em <http://www.biologico.agricultura.sp.gov.br/ artigos_ok.php?id_artigo=101> Acesso em 4 dez. 2016.

O'reilly K.M., Green L.E., Malone F.E. \& Medley G.F. 2008. Parameter estimation and simulations of a mathematical model of Corynebacterium pseudotuberculosis transmission in sheep. Prev. Vet. Med. 83(3/4):242-259. <http://dx.doi.org/10.1016/j.prevetmed.2007.08.002><PMid:18164500>

Oreiby A.F. 2015. Diagnosis of caseous lymphadenitis in sheep and goat. Small Ruminant Res. 123(1):160-166. <http://dx.doi.org/10.1016/j. smallrumres.2014.11.013>

Paton M.W., Rose I.R., Hart R.A., Sutherland S.S., Mercy A.R., Ellis T.M. \& Dhaliwal J.A. 1994. New infection with Corynebacterium pseudotuberculosis reduces wool production. Aust. Vet. J. 71(2):47-49. <http://dx.doi. org/10.1111/j.1751-0813.1994.tb06152.x><PMid:8166614>

Paule B.J.A., Meyer R., Moura-Costa L.F., Bahia R.C., Carminati R., Regis L.F., Vale V.L.C., Freire S.M., Nascimento I., Schaer R. \& Azevedo V. 2004. Threephase partitioning as an efficient method for extraction/concentration of immunoreactive excreted-secreted proteins of Corynebacterium pseudotuberculosis. Protein, Expression and Purification 34(2):311-316. <http://dx.doi.org/10.1016/j.pep.2003.12.003><PMid:15003266>

Pinheiro R.R., Gouveia A.M.G., Alves F.S.F. \& Haddad J.P.A. 2000. Aspectos epidemiológicos da caprinocultura cearense. Arq. Bras. Med. Vet. Zootec. 52(5):534-543. <http://dx.doi.org/10.1590/S0102-09352000000500021>

Ribeiro D. 2009. Análise comparativa de métodos de diagnóstico para linfadenite caseosa em ovinos sintomáticos e assintomáticos. Dissertação Mestrado. Disponível em <http://200.145.6.238/bitstream/handle/11449/92211/ ribeiro_d_me_araca.pdf?sequence=1\&isAllowed=y> Acesso em 18 dez. 2016.

SEBRAE 2009. Manejo básico de ovinos e caprinos. SEBRAE, Brasília/DF. 146p.

Seyffert N., Guimarães A.S., Pacheco L.G.C., Portela R.W., Bastos B.L., Dorella F.A., Heinemann M.B., Lage A.P., Gouveia A.M.G., Meyer R., Miyoshi A. \& Azevedo V. 2010. High seroprevalence of caseous lymphadenitis in Brazilian goat herds revealed by Corynebacterium pseudotuberculosis secreted proteins-based ELISA. Res. Vet. Sci. 88(1):50-55. <http://dx.doi. org/10.1016/j.rvsc.2009.07.002><PMid:19665155>

Silva L.F.N. 2014. Perfil de produtores da associação de criadores de cabras leiteiras do Leste e Agreste Potiguar. Dissertação de Mestrado. Disponível em <https://repositorio.ufrn.br/jspui/handle/123456789/19623> Acesso em 18 dez. 2016.

Souza M.F., Carvalho A.Q., Garino Junior J.R.F. \& Riet-Correa F. 2011. Linfadenite caseosa em ovinos deslanados abatidos em um frigorifico da Paraíba. Pesq. Vet. Bras. 31(3):224-230. <http://dx.doi.org/10.1590/ S0100-736X2011000300007>

Sting R., Wagner B., Sari-Turan A., Stermann M., Reule M., Eichner M. \& Beyer W. 2012. Serological studies on Corynebacterium pseudotuberculosis infections in goats in Baden-Wuerttemberg (Germany) and seroreactions on antigens used for newly developed Enzyme-Linked Immunosorbent Assays (ELISA). Berliner und Munchener Tierarztliche Wochenschrift. Berlim 125(1/2):67-75. <PMid:22372327>

Teixeira R. 2009. Cabra nossa de cada dia. Ediç̃oes UVA, Sobral, CE.

Thrusfield M. 2007. Veterinary Epidemiology. 3rd ed. Blackwell Science, Oxford. 624p. 